University of Wollongong

Research Online

Australian Institute for Innovative Materials -

Papers

Australian Institute for Innovative Materials

$1-1-2015$

Development and characterization of novel hybrid hydrogel fibers

Azadeh Mirabedini

University of Wollongong

Javad Foroughi

University of Wollongong, foroughi@uow.edu.au

Anthony C. Romeo

University of Wollongong, tromeo@uow.edu.au

Gordon G. Wallace

University of Wollongong, gwallace@uow.edu.au

Follow this and additional works at: https://ro.uow.edu.au/aiimpapers

Part of the Engineering Commons, and the Physical Sciences and Mathematics Commons

Research Online is the open access institutional repository for the University of Wollongong. For further information contact the UOW Library: research-pubs@uow.edu.au 


\title{
Development and characterization of novel hybrid hydrogel fibers
}

\begin{abstract}
Biopolymeric continuous core-sheath fibres, with an inner core of chitosan and alginate as the sheath, were fabricated for the first time without using a template. Hereby, the necessary conditions to achieve chitosan-alginate core-sheath fibre via a wet-spinning process are presented. SEM micrographs show the cylinder-shaped monofilament structure of the chitosan core surrounded by the alginate sheath. The coaxial fibres exhibit a $260 \%$ increase in ultimate stress and more than $300 \%$ enhancement in the Young's modulus compared to the alginate counterpart. Release profiles from the coaxial fibre were determined using a model component. The obtained results suggest that the fibres are likely to find applications as $3 \mathrm{D}$ tissue scaffolds capable of drug delivery.
\end{abstract}

\section{Keywords}

characterization, novel, development, hybrid, fibers, hydrogel

Disciplines

Engineering | Physical Sciences and Mathematics

\section{Publication Details}

Mirabedini, A., Foroughi, J., Romeo, T. \& Wallace, G. G. (2015). Development and characterization of novel hybrid hydrogel fibers. Macromolecular Materials and Engineering, 300 (12), 1217-1225. 
DOI: $10.1002 /$ marc. ((Insert number))

Article Type: Full Paper

\title{
Development and Characterization of Novel Hybrid Hydrogel Fibres
}

Azadeh Mirabedini, Javad Foroughi*, Tony Romeo, Gordon G. Wallace*

\begin{abstract}
Biopolymeric continuous core-sheath fibres, with an inner core of chitosan and alginate as the sheath, were fabricated for the first time without using a template via a wet-spinning process. We hereby present the necessary conditions to achieve chitosan-alginate core-sheath fibre. SEM images clearly show the cylinder shaped monofilament porous structure of the chitosan core surrounded by the alginate sheath. Coaxial fibres of chitosan/alginate exhibit a $260 \%$ increase in ultimate stress and more than 300\% enhancement in the Young's modulus compared to the alginate counterpart. The swelling ratio of as-prepared fibres has been investigated in Simulated Biological Fluid (SBF). Release profiles from the coaxial fibre were determined using Toluidine Blue as a model component. Unlimited length of coaxial biofibres could be produced which provides the opportunity to create $3 \mathrm{D}$ structures from them. The results obtained also suggest they are likely to find applications as tissue scaffolds capable of drug delivery.
\end{abstract}

A. M. Author-One, Dr. J. F., Author-Two, T. R., Author-Three, G. G. W., Author-Four.

ARC Centre of Excellence for Electromaterials Science, Intelligent Polymer Research Institute, AIIM Facility, University of Wollongong, Fairy Meadow, NSW 2519, Australia

am707@uowmail.edu.au

foroughi@uow.edu.au

tromeo@uow.edu.au

gwallace@uow.edu.au

Keywords: coaxial fibres, wet-spinning, hydrogel, chitosan, alginate, bioscaffolds, drug release 


\section{Introduction}

Biopolymers are commonly used in clinical and biological applications for tissue engineering purposes. ${ }^{[1-15]}$ Chitosan and alginate are promising, naturally occurring, biopolymers. They possess several unique properties including biodegradability, biocompatibility, low toxicity, low immunogenicity and antimicrobial activity. ${ }^{[16]}$ These biopolymers can be obtained from different sources such as microbial and animal ${ }^{[17]}$ and are used in various applications such as wound dressings, ${ }^{[18-22]}$ tissue scaffolds, ${ }^{[23-30]}$ cell encapsulation, ${ }^{[31,32]}$ drug delivery ${ }^{[33-39]}$ and also as cell delivery vehicles. ${ }^{[40]}$ Due to their simple processability, they can be fabricated in various forms such as gels, fibres, nano and microspheres and scaffolds. ${ }^{[13,41]}$ An ongoing quest of several investigators is focused towards tissue engineering and repair through the transplantation of cells seeded onto biodegradable polymer scaffolds. ${ }^{[42-44]}$

Chitosan and alginate are two of the most important members of the "polysaccharides from non-human origin" group. ${ }^{[45]}$ Chitosan is a cationic polymer derived from crustacean skeletons, while alginic acid is an anionic polymer, typically derived from brown algae. ${ }^{[46]}$ Alginate is a linear, binary copolymer composed of 1, 4-linked $\beta$-D-mannuronic acid (M) and $\alpha$-L-guluronic acid $(\mathrm{G})$ monomers. The composition of alginate (the ratio of the two uronic acids and their sequential arrangements) varies with the source. Salts of alginic acid with monovalent cations such as sodium alginate are all soluble in water. ${ }^{[47]}$ The high acid content allows alginic acid to undergo spontaneous and mild gelling in the presence of divalent cations, such as calcium ions. However, calcium alginate fibres have proven to be unstable structures as tissue scaffolds or drug vehicles for in-vivo usages due to its tendency to swell and dissolve in various ionic solutions which are present in the body. ${ }^{[48,49]}$ Structurally, chitosan is a semi-synthetically derived aminopolysaccharide which is the $\mathrm{N}$-deacetylated product of chitin, i.e. poly- $(1 \rightarrow 4)-2$-amino-2-deoxy- $\beta$-D-glucose..$^{[1,46,50,51]}$ This hydrogel is highly reactive due to free amine groups and is readily soluble in weakly acidic solutions 
resulting in the formation of a cationic polymer with a high charge density. ${ }^{[52-55]}$ Chitosan can be produced in a variety of forms including films, fibres, nanoparticles and microspheres. Nevertheless the strong alkaline condition $(\mathrm{pH}>12)$ needed to form chitosan-based structures, can limit its utilization for loading most of drugs or bioactive molecules into it. Chitosan can also form ionic complexes with water-soluble anionic polymers such as alginate. Therefore, there has been an increased interest in fabricating alginate-chitosan polyion systems for several bioapplications such as cartilage and bone regeneration. ${ }^{[56]}$ Both alginate and chitosan have been approved by the FDA for clinical use. Incorporating these two materials together in the one structure allows us to form polyanion-polycation complexes. ${ }^{[57]}$ The alginate/chitosan polyelectrolyte complex has combined properties of the two individual components, such as more stable to $\mathrm{pH}$ change for shape-keeping than alginate or chitosan alone in aqueous medium ${ }^{[58]}$ alongside providing the opportunity to use it as drug-loaded bioscaffolds. Chitosan-alginate hybrid polymer structures have also been shown to promote biological responses including enhancing cell attachment and proliferation. ${ }^{[59]}$

Synthetic fibres are usually made via one of four typical spinning methods - wet-spinning, melt-spinning, dry-spinning or electrospinning. Wet spinning is the oldest among the four processes and is generally used to produce natural fibres that cannot be formed by either melt or dry-spinning. ${ }^{[51]}$ Wet-spinning is the preferred approach for both chitosan ${ }^{[60,61]}$ and alginate $^{[62]}$ fibres because it maintains the strong interchain hydroxyl forces in their chemical structure.

Tissue scaffolds can be synthesised from synthetic or biologically based bioresorbable polymers that act as a functional or inert framework for missing or malfunctioning human tissues and organs. The primary role of a scaffold is to provide a temporary substrate to which cells can adhere. ${ }^{[63]}$ A scaffold should ideally promote attachment, migration, proliferation and differentiation of cells, as appropriate. ${ }^{[63]}$ To achieve this, scaffolds must 
have certain physical characteristics tailored to tissue requirements, such as porosity, structural integrity, defined pore size and controlled degradability. Furthermore, the scaffold should provide the optimal biochemical microenvironment for the seeded cells. Porous chitosan matrix has been used as a scaffold for skin, ${ }^{[2,3,64]}$ liver, ${ }^{[4]}$ bone and cartilage, ${ }^{[6-9]}$ cardiac, ${ }^{[10,11,65]}$ corneal $^{[66]}$ and vascular regenerative tissue remodelling. ${ }^{[13,67,68]}$ In addition, alginate has been extensively used as a scaffold for liver, ${ }^{[15]}$ bone, ${ }^{[69]}$ nerve ${ }^{[70]}$ and cartilage engineering. ${ }^{[71]}$

In this study, a new wet spinning approach is developed that employs a co-axial spinneret for production of chitosan/alginate core-sheath fibres for the first time. This research explores the conditions necessary to achieve optimal properties of the chitosan-alginate core-sheath fibre in one-step spinning. The secondary aim of this research was to investigate the mechanical and swelling properties of these fibres in order to optimize them for use in biomedical applications. Significantly improved mechanical and swelling properties of coaxial alginatechitosan fibres, compared to their alginate counterparts were reported.

\section{Experimental}

\subsection{Fibre Preparation}

\subsubsection{Materials}

Chitosan (medium molecular weight with a degree of deacetylation of about $80.0 \%$ ) and alginic acid sodium salt from brown algae (medium molecular weight) were obtained from Sigma-Aldrich Co. LLC. Acetic acid was supplied from Ajax Finechem and used directly without further purification. Calcium chloride fused dihydrate (molecular weight of 147.02 obtained from Chem-supply) was used as the coagulating agent. Sodium hydroxide pellets (obtained from Ajax Finechem) was also used as the coagulating agent. Isopropanol was obtained from Merck Chemicals. Toluidine Blue O (also known as toluidine blue or TB) as a technical grade was supplied from Sigma-Aldrich for the release experiments. 
A simulated body fluid (SBF) solution, with ion concentrations approximately equal to those of human blood plasma, was prepared with the following ion concentrations of $142 \mathrm{mM} \mathrm{Na}^{+}$, $5 \mathrm{mM} \mathrm{K}^{+}, 1.5 \mathrm{mM} \mathrm{Mg}^{2+}, 2.5 \mathrm{mM} \mathrm{Ca}^{2+}, 10^{3} \mathrm{mM} \mathrm{Cl}^{-}, 27 \mathrm{mM} \mathrm{HCO}_{3}^{-}, 1.0 \mathrm{mM} \mathrm{HPO}^{2-}$ and 0.5 $\mathrm{mM} \mathrm{SO} 4^{2-}$ with the final adjusted $\mathrm{pH}$ of $7.4 \pm 0.05$. $^{[26]}$ This solution was used as an aqueous medium to re-swell the dried fibres for imaging them in wet-state.

\subsubsection{Preparation of the spinning solutions}

Chitosan powder $3 \%\left(\mathrm{w} \mathrm{v}^{-1}\right)$ was dissolved in water containing $2.5 \%\left(\mathrm{v} \mathrm{v}^{-1}\right)$ acetic acid. The powder was dissolved in water and stirred overnight at a temperature of $\sim 45{ }^{\circ} \mathrm{C}$ to form a homogenous solution. For the purpose of coaxial spinning, chitosan solution was prepared with three different concentrations of calcium chloride, $0.5,1$ and $2 \%\left(\mathrm{w} \mathrm{v}^{-1}\right)$, as the crosslinking agent for the sodium alginate.

Alginate spinning solution was produced by dissolving alginate powder in water while stirring overnight at $\sim 50{ }^{\circ} \mathrm{C}$ to provide homogeneity for the spinning. The sodium alginate in solution was then precipitated in a bath of aqueous calcium chloride (Ethanol/ $\mathrm{H}_{2} \mathrm{O}$ 1:5).

\subsubsection{Wet-spinning of chitosan, alginate and Chit-Alg coaxial fibres}

Wet-spun chitosan fibres were produced in a basic coagulation bath of $1 \mathrm{M}$ sodium hydroxide $(\mathrm{NaOH})$. Uniform alginate fibres were also spun in a $2 \% \mathrm{CaCl}_{2}$ coagulation bath. Coresheath fibres of chitosan-alginate (Chit-Alg) were successfully spun using a coaxial spinneret. For this purpose, a novel coaxial spinneret with two input ports was designed (Figure 1). Chitosan spinning solution (mixed with different amounts of $\mathrm{CaCl}_{2}$ ) was injected through port B and extruded through the centre outlet nozzle into the coagulation bath of aqueous calcium chloride (Ethanol/ $\mathrm{H}_{2} \mathrm{O}$ 1:5). Simultaneously, alginate spinning solution was extruded as the sheath of the fibre, providing an outer casing for the chitosan core, by injection through port A which facilitates extrusion through the outer segment of the spinneret nozzle. In this method, by using a blend of chitosan with various percentages of calcium chloride, it is 
possible that the alginate sheath can be coagulated from the inner chitosan core, while also creating the opportunity to react chitosan with sodium alginate at a much faster rate.

A schematic of the coaxial wet-spinning setup is also shown in Figure 1. The setup consists of two injection syringes and pumps (KDS100, KD Scientific Inc.), connected to port A and B of the predesigned coaxial spinneret, a coagulation bath and a stretching collector (Nakamura Service Co.). The preparation of coaxial fibres without incorporating a certain amount of $\mathrm{CaCl}_{2}$ did not turn out to be successful as tried. Therefore, as mentioned earlier chitosan solutions including $0.5,1$ and $2 \%\left(\mathrm{w} \mathrm{v}^{-1}\right) \mathrm{CaCl}_{2}$ were prepared for the core component of the fibres and alginate the sheath. The samples are named here as Chit-Alg (0.5), Chit-Alg (1) and Chit-Alg (2). Solutions were delivered at flow rates of $14 \mathrm{~mL} \mathrm{~h}^{-1}$ for chitosan and $25 \mathrm{~mL}$ $\mathrm{h}^{-1}$ for the sheath. Coaxial fibres of Chit-Alg (1) were then used for all imaging characterization tests.

\section{Figure 1}

TB was used as an indicative dye to be incorporated into the coaxial fibres to track the release experiment. For the purpose of fibre preparation for release experiments, $0.001 \%\left(\mathrm{w} \mathrm{v}^{-1}\right)$ of TB was added to previously made aqueous chitosan $3 \%\left(\mathrm{w} \mathrm{v}^{-1}\right)$ and alginate $3 \%\left(\mathrm{w} \mathrm{v}^{-1}\right)$ solutions. These solutions were then spun into the same coagulation baths which were previously used to make pristine fibres. Coaxial fibres containing TB were also fabricated using the method mentioned previously with the small difference of using chitosan/TB solution as the core component.

\subsection{Characterization Methods}

\subsubsection{Viscometry of spinning solution}

Viscosity changes in both chitosan $3 \%\left(\mathrm{w} \mathrm{v}^{-1}\right)$ and alginate $3 \%\left(\mathrm{w} \mathrm{v}^{-1}\right)$ solutions were measured in flow mode (cone and plate method) by Rheometer- AR G2 (TA Instruments, 
USA). Shear viscosity measurements were carried out three times for each sample at room temperature $\left(\sim 25^{\circ} \mathrm{C}\right)$ and with the shear rates between $0.1-500\left(\mathrm{~S}^{-1}\right)$.

\subsubsection{Stereomicroscope observation}

Digital images and measurements of prepared fibres (in their wet state) were obtained and fibre diameters were measured using a LEICA M205 stereomicroscope and LAS 4.4 software.

\subsubsection{Low Vacuum Scanning Electron Microscopy (LVSEM)}

The morphology of fibres, surface and cross-sectional structure, were examined in a JSM6490LV SEM. Samples were prepared for imaging by immersion in SBF (for about 30 minutes) beforehand and then short lengths (about $5 \mathrm{~mm}$ ) were removed, drained of excess medium and inserted into holes ( 1 or $1.5 \mathrm{~mm}$ diameter) which had been pre-drilled into a small brass block (approximately $25 \mathrm{~mm}$ diameter x 10mm) (See Figure 1(a) in supporting information section). The holes allow the fibres to be inserted upright and protrude from the brass block (See Figure 1(b) in supporting information). The block containing the mounted fibres was then plunged into liquid nitrogen for about 45 seconds and a liquid nitrogen cooled razor blade was run across the surface of the block to fracture the fibres. The block was then quickly transferred to the LVSEM for examination. SEM images were taken in HV mode at $15 \mathrm{kV}$ operating voltage and a spot size setting of 45 . Due to their inherent water content, the fibres remained conductive for a period of 25 - 30 mins in the SEM vacuum and so no coating was required.

\subsubsection{Dynamic Mechanical Analysis}

Tensile tests were carried out on a Dynamic Mechanical Tester (EZ-L Tester from Shimadzu, Japan), at $2 \mathrm{~mm} \mathrm{~min}^{-1}$ and a gauge length of $11.5 \mathrm{~mm}$. Average values of tensile strength and maximum strain were determined after repeating the test three times.

2.2.5. Thermogravimetric Analysis (TGA) 
TGA was used to determine the decomposition temperature of both materials in produced fibres. As a result, the weight ratio of each hydrogel involved in forming the fibres can be roughly determined. Thermogravimetric measurements were made using a TA instruments Thermogravimetric Analyser (TGA) model TGA/SDTA851e. The temperature range studied was $25-800{ }^{\circ} \mathrm{C}$ at the heating rate of $2{ }^{\circ} \mathrm{C} \mathrm{min}^{-1}$ under an air atmosphere. The mass of the sample pan was continuously recorded as a function of temperature.

\subsubsection{Toluidine Blue $(\mathrm{TB})$ release measurement}

The release behavior of the prepared fibres for drug release applications was evaluated using TB as a model dye introduced into the fibres. The amount of released TB was determined via UV-vis spectroscopy by monitoring the absorption of TB at its $\lambda_{\max } 630 \mathrm{~nm}$ in SBF (pH 7.4, total volume is $1 \mathrm{~mL}$ ). To construct an absorbance calibration curve for sample analysis using a Shimadzu UV 1601 spectrophotometer, UV-vis spectra of SBF solutions containing TB with different concentrations were recorded between $200 \mathrm{~nm}$ and $1100 \mathrm{~nm}$. The dye was mixed with chitosan solution before spinning with the concentration of $0.1 \%\left(\mathrm{w} \mathrm{v}^{-1}\right)$ and then injected as the core component while spinning to prepare the samples for the release experiment.

Approximately $5 \mathrm{~cm}$ of each dried sample (in triplicate) was placed in a $2 \mathrm{~mL}$ Eppendorf tube and $1 \mathrm{~mL}$ of SBF was added into it. The release medium was taken by micro-pipette at specific time points over 5 days and replaced with the same volume of fresh SBF solution to maintain the total volume constant. The percentage of released TB (\%) was plotted versus time.

\section{Results and Discussion}

Initial investigations were aimed at determining the spinnability and the physical characteristics of potential wet spinning dopes to ensure they were in the range required for fibre formation. 


\subsection{Spinnability vs. Concentration}

Spinnable concentrations have been reported for chitosan varying from $2-15 \%\left(\mathrm{w} \mathrm{v}^{-1}\right) .^{[16,20]}$ Here, we found that $2-6 \%\left(\mathrm{w} \mathrm{v}^{-1}\right)$ is the optimum concentration range for wet-spinning into a coagulation bath of $1 \mathrm{M}$ sodium hydroxide. Observations also indicated that aqueous alginate solutions at a concentration of below $2 \%\left(\mathrm{w} \mathrm{v}^{-1}\right)$ would not generate a continuous fibrous structure via wet-spinning; increasing the alginate concentration from 2 to $4 \%\left(\mathrm{w} \mathrm{v}^{-1}\right)$, the solution became highly spinnable. Then again, at concentrations above $4 \%\left(\mathrm{w} \mathrm{v}^{-1}\right)$, the solution became highly viscous which imped continuous flow through the needle, rendering the solution unspinnable. A concentration of $3 \%\left(\mathrm{w} \mathrm{v}^{-1}\right)$ has been selected for both hydrogel solutions due to the ease of spinnability, together with maintaining the suitable mechanical properties for coaxial wet-spinning. In brief, the concentrations of spinning solutions were kept constant to study the effect of spinning parameters such as injection rate and the amount of calcium chloride inside the coagulation bath as well as amount mixed with chitosan solutions.

\subsection{Rheology}

Viscosity is considered the most critical factor for the selection of suitable concentrations of chitosan and alginate solutions for fibre spinning. For coaxial spinning matching viscosities of the two components is also a consideration.

Figure 2 shows changes in viscosity versus shear rate was determined from aqueous solutions of chitosan at $3 \%\left(\mathrm{w} \mathrm{v}^{-1}\right)$ and alginate at $3 \%\left(\mathrm{w} \mathrm{v}^{-1}\right)$. Spinning solutions of $3 \%\left(\mathrm{w} \mathrm{v}^{-1}\right)$ chitosan resulted in a solution with a viscosity of 6.4 Pa.s. The viscosity of $3 \%\left(\mathrm{w} \mathrm{v}^{-1}\right)$ sodium alginate solution was approximately 8.5 Pa.s. The viscosities of the two solutions became closer as the shear rate increased. Under shear, hydrogel chains are in a less expanded conformation and become less entangled causing the viscosity to drop. At the time of spinning, chitosan is injected with rate of $14 \mathrm{~mL} \mathrm{~h}^{-1}$ while the injection rate is $25 \mathrm{~mL} \mathrm{~h}^{-1}$ for 
the alginate solution. Considering the outlet sectional area diameter, the output flow rate was calculated according to the equation, $Q=V A$ where $Q$ represents the volumetric flow rate, $V$ the linear injection velocity and $A$ the cross-sectional area of spinneret head $\left(\mathrm{m}^{2}\right)$. The flow rates calculated to be about $\sim 97 \mathrm{~S}^{-1}$ for alginate and $\sim 75 \mathrm{~S}^{-1}$ for chitosan solutions which resulted in a viscosity of $\sim 2.5$ Pa.s for chitosan and $\sim 2.8$ Pa.s for alginate solutions. These outcomes seem to be ideal for coaxial spinning.

\section{Figure 2}

\subsection{Continuous Spinning of Coaxial Fibres}

To produce continuous uniform fibres, chitosan with rate of $14 \mathrm{~mL} \mathrm{~h}^{-1}$ and alginate solution with rate of $25 \mathrm{~mL} \mathrm{~h}^{-1}$ have been simultaneously injected into the $2 \%\left(\mathrm{w} \mathrm{v}^{-1}\right)$ aqueous $\mathrm{CaCl}_{2}$ coagulation bath through the ports built in the coaxial spinneret. The spinning method to achieve the optimal properties was described in section 2.1.3 in detail, previously. Using this method, unlimited length of fibres could be obtained which was collected using a collector as shown in Figure 3.

\section{Figure 3}

As-prepared fibres were mechanically strong and flexible enough to create a woven structure. The woven structure of Chit-Alg fibres (containing TB) in dry and wet state were shown in Figure 4(a) and (b), respectively. This capability provides the potential for these structures to be utilized as tissue scaffolds and drug delivery vehicles applications.

\section{Figure 4}

\subsection{Morphology of As-prepared Fibres}

The stereomicroscope images of wet-spun chitosan, alginate and core-sheath chitosan/Alginate fibres are shown in Figure 5 in wet and dry-states. As can be seen in Figure 5(a) and (b), the surface of chitosan fibre seemed to be very smooth and soft, while some wrinkles can be noticed spreading on the surface of the alginate fibre which will be increased 
during the fibre drying process. Moreover, one can see that the core-sheath fibres are straight and smooth with a core loaded in the centre of fibres, have a uniform structure and diameter of ca. $220 \mu \mathrm{m}$ and $136 \mu \mathrm{m}$ for the sheath and core when wet, respectively (Figure 5(c)). However, the dried fibres hold the thickness of $\sim 140 \pm 10 \mu \mathrm{m}$ (This average value was calculated after measuring the diameter under the stereomicroscope ten times). In addition, some lines or longitudinal indentations can be observed running parallel with the fibres on totally dried core-sheath fibre as shown in Figure 5(d). The Chitosan core is $\sim 90 \mu \mathrm{m}$ which is surrounded by a thin layer of Alginate sheath of $\sim 8-12 \mu \mathrm{m}$. Still, the thicknesses of core and sheath materials are adjustable changing solution rates and drawing ratio.

\section{Figure 5}

LV-SEM images of cross-sections and the surfaces of solid and core-sheath fibres are illustrated in Figure 6(a-e). They give valuable information about the morphology of the two polymers. Before imaging fibres were immersed in SBF and imaged with LV-SEM in an attempt to capture structural information in the "wet-state", since that is how they would be used in future possible applications.

\section{Figure 6}

Cross-sections of solid fibres fabricated based on spinning conditions mentioned in section 2.1.3, clearly show the cylinder shaped form of the hydrated chitosan and alginate solid fibres (Figure 6(a) and (b), respectively). Alginate fibres looked completely porous and spongy, while the cross section of chitosan fibres appeared to be quite dense. In contrast, crosssections of the coaxial fibres reveal slightly irregular, oval shaped fibres with a distinct separation between chitosan in the core and the outer alginate sheath as is indicated in Figure 6(c). In addition, both polymers show an extensive porous structure in the coaxial structure. On the cross-section of chitosan, regular crystalline structures can be seen which are probably due to the presence of calcium chloride inside the core (Figure 6(d), while alginate has a 
honeycomb structure (Figure 6(e)). It is evident that the fibre is composed of two distinct areas, with minimal interaction at the interface of the chitosan and alginate.

\subsection{Mechanical Properties of As-prepared Fibres}

The mechanical properties of alginate, chitosan and Chit-Alg coaxial fibres employing different concentrations of calcium chloride in chitosan core spinning dope are depicted in Figure 7. Ultimate stresses (MPa), ultimate strains (\%), Young's moduli (MPa) and swelling ratios (\%) were measured for alginate, chitosan, Chit-Alg (0.5), Chit-Alg (1) and Chit-Alg (2) fibres, respectively.

\section{Figure 7}

Mechanical analysis results revealed that with addition of more calcium chloride to the coredope, Young's modulus decreased. Increasing the amount of calcium chloride into fibre core will probably cause to make agglomerations which can lead to phase separation. Thus, the mechanical properties of as-prepared fibres such as Young's modulus and ultimate stress were decreased.

\section{Table 1}

The results, which are presented in Table 1, also confirmed the reinforcing role played by the chitosan core in coaxial Chit-Alg fibres. Young's modulus was measured to be about 17 and $70 \mathrm{MPa}$ for alginate and chitosan solid fibres, respectively. It has been also revealed that the fibres which contain $1 \%\left(\mathrm{w} \mathrm{v}^{-1}\right) \mathrm{CaCl}_{2}$ resulted in the highest mechanical results due to their modulus and ultimate stress compared to other coaxial fibres.

\subsection{Swelling Properties in SBF}

The swelling properties of the fibres were determined in SBF medium over a period of 48 hours. Fibre diameters were measured at different time intervals. Results are shown in Figure 8 and listed in Table 1.

\section{Figure 8}


It can be seen in Figure 8 that fibres containing $0.5 \%\left(\mathrm{w} \mathrm{v}^{-1}\right)$ calcium chloride have shown the least amount of initial swelling, while fibres with $1 \%\left(\mathrm{w} \mathrm{v}^{-1}\right)$ calcium chloride in the core demonstrated the highest degree of swelling. It seems that two simultaneous events are occurring by increasing the calcium chloride content in the core (from 0.5 to $2 \%\left(\mathrm{w} \mathrm{v}^{-1}\right)$ ). Increasing the number of ionic groups $\left(\mathrm{Ca}^{2+}\right)$ in hydrogels is known to increase their swelling capacity. ${ }^{[1]}$ This is mainly due to the simultaneous increase of the number of counterions inside the gel, which produces an additional osmotic pressure that swells the gel as described in Flory theory previously. ${ }^{[2]}$ Therefore, by adding more calcium chloride to the chitosan solution the degree of swelling increases. On the other hand, increasing the amount of $\mathrm{Ca}^{2+}$ ions also results in an increase in the ion exchange process within the sodium alginate. In fact, the ratio of calcium will increase in the alginate. The increase of the crosslinking agent concentration leads to the formation of a hydrogel with a greater 3D network density and so results in sheaths which show less swelling.

\subsection{Thermogravimetric Analysis}

TGA was employed as a method to determine the weight ratio of each hydrogel involved in forming the coaxial fibres based on the decomposition temperature of both materials. Thermogravimetric measurements were studied in the temperature range of $25-800{ }^{\circ} \mathrm{C}$ at a heating rate of $2{ }^{\circ} \mathrm{C} \min ^{-1}$ under air atmosphere. Thermal properties of as-prepared and alginate and chitosan and Chit-Alg (1) fibres are shown in Figure 9 (See Fig. 2 in supporting information for comparison between all prepared fibres).

\section{Figure 9}

As depicted in Figure 9, both chitosan and alginate showed almost the similar thermal behaviour below $300{ }^{\circ} \mathrm{C}$. Alginate showed two main drops while heating at about $220{ }^{\circ} \mathrm{C}$ and $540{ }^{\circ} \mathrm{C}$. The salt decomposed by dehydration followed by degradation to $\mathrm{Na}_{2} \mathrm{CO}_{3}$ at around $220{ }^{\circ} \mathrm{C}$ that decomposes in $\mathrm{N}_{2}$ and there was also a carbonized material that decomposes 
slowly at about $540{ }^{\circ} \mathrm{C}$ in air. According to study published by Newkirk et al., ${ }^{[72]}$ the $\mathrm{Na}_{2} \mathrm{CO}_{3}$ decomposition is dependent on the sample holder and atmosphere used. They reported that under $\mathrm{N}_{2}$ the dehydration occurs in a similar way, but the decomposition of the carbonized material is slower at around $750{ }^{\circ} \mathrm{C}$, resulting in $\mathrm{Na}_{2} \mathrm{CO}_{3} \cdot{ }^{[73]}$ Two weight losses are also observed in the TGA curve of chitosan. The first stage occurs at about $270{ }^{\circ} \mathrm{C}$ with a corresponding weight loss of about $52 \%$ which is attributed to the decomposition of chitosan. The second weight loss is around $460{ }^{\circ} \mathrm{C}$, where a carbonized material will be decomposed in air. The total weight loss of alginate sample at about $800{ }^{\circ} \mathrm{C}$ is $70 \%$, while it is more than 98\% for chitosan. Looking at Fig.9, coaxial fibres had thermal properties and total weight loss occurring between the values observed for chitosan and alginate. At around $500{ }^{\circ} \mathrm{C}$, only a negligible weight percentage of the chitosan fibre has been left. Consequently, the remained ingredients at this temperature are mainly from the alginate fibre which is about $28-40 \%$ wt. for the coaxial structures. These results indicate that the coaxial structures contain about 60$70 \%$ wt. of the chitosan core and $30-40 \%$ wt. of alginate sheath when dried completely. A vigorous liberation of $\mathrm{CO}_{2}$ was observed while a dark insoluble residue remained in the test tube, in both cases.

\subsection{In-vitro Release Measurement}

The calibration curve was determined by monitoring the absorption of TB at its $\lambda_{\max }(630 \mathrm{~nm})$ in SBF with various concentrations of TB using UV-vis spectroscopy.

The release profiles of TB from dye loaded coaxial fibres were plotted versus time and are demonstrated in Figure 10. The whole release time period varied for different types of fibres including alginate, chitosan and the core-sheath fibre depending on the period over which they could resist the media before their structure fell apart. As can be seen in Figure 10, the coaxial fibres showed similar release behaviour to that of the chitosan fibres. But, they could stand the media in a shorter period of time without losing the initial structure. 


\section{Figure 10}

Wet-spinning of chitosan fibre is needed to be done in basic coagulation bath with $\mathrm{pH}$ over 12 which is not an appropriate condition for most of loaded drugs. Coaxial fibres indicated a controlled manner of release more or less like chitosan fibres. However, their fabrication process via wet-spinning is performed in a neutral coagulation bath. These results provide the suitable condition to load any types of drugs into the wet-spun fibres for drug delivery applications.

\section{Conclusion}

The production of coaxial biofibres has been successfully developed for the first time using a wet-spinning method. The morphological, mechanical, thermal and swelling properties of these fibres are discussed. Enhanced mechanical properties of $260 \%$ in ultimate stress and more than $300 \%$ in the Young's modulus were observed by incorporating $1 \%\left(\mathrm{w} \mathrm{v}^{-1}\right) \mathrm{CaCl}_{2}$ into the chitosan core. SEM micrographs of the cross-section of chitosan-alginate fibres clearly show the cylinder shaped monofilament form of the chitosan fibre covered with alginate. These biofibres as delivery platforms have demonstrated great potentials toward advancing current drug delivery systems. Hybrid chitosan/alginate fibres could likely be promising as a novel kind of 3D bioscaffolds in drug release studies or tissue engineering.

\section{Acknowledgements}

This work was supported by funding from Australian Research Council Centre of Excellence Scheme (Project Number CE 140100012), Australian Laureate Fellowship scheme (FL110100196) and the Australian Research Council under Discovery Early Career Researcher award (Javad Foroughi DE12010517). This research used equipment funded by Australian Research Council grants and located at the UOW Electron Microscopy Centre. 
The authors would also like to thank Saber Mostafavian for 3D design of the wet-spinning process.

\section{References}

[1] Y. Kimura, A. Hokugo, T. Takamoto, Y. Tabata, H. Kurosawa, Tissue Eng. 2008, 14, 47.

[2] C. Han, L. Zhang, J. Sun, H. Shi, J. Zhou, C. Gao, Biomed. \& Biotechnol. 2010, 11, 524.

[3] L. Ma, C. Gao, Z. Mao, J. Zhou, J. Shen, Biomater. 2003, 24, 4833.

[4] X. Wang, Y. Yan, Z. Xiong, F. Lin, R. Wu, R. Zhang, Q. Lu, J. Biomed. Mater. Res. B Appl. Biomater. 2005, 75B, 91.

[5] S. Seo, D. Ph, Y. Choi, T. Akaike, Tissue Eng. 2006, 12, 33.

[6] M. Iqbal, S. Æ. Xiaoxue, J. Mater. Sci. 2009, 44, 5713.

[7] T. H. Ang, F. S. A. Sultana, D. W. Hutmacher, Y. S. Wong, J. Y. H. Fuh, Mater. Sci. Eng. C 2002, 20, 35 .

[8] A. A. Abbas, S. Y. Lee, L. Selvaratnam, N. Yusof, T. Kamarul, Eur. Cell. Mater. 2008, 16, 3042.

[9] N. M. Breyner, A. A. Zonari, J. L. Carvalho, V. S. Gomide, D. Gomes, A. M. Góes, In Biomaterials Science and Engineering; 2009; pp. 211-226.

[10] A. Martins, R. L. Reis, N. M. Neves, Nanomedi. 2007, 2, 929.

[11] T. Zhang, L. Q. Wan, Z. Xiong, A. Marsano, R. Maidhof, M. Park, Y. Yan, G. Vunjaknovakovic, J. Tissue Eng. Regen. Med. 2012, 6, 748.

[12] T. Wang, I. Wang, J. Lu, T. Young, Mol. Vis. 2012, 18, 255.

[13] K. I. Draget, P. O. Smidsrùd, P. G. Skjåk-brñk, In Polysccharides and Polyamides in the Food Industry. Properties, Production and Patents.; 2005; pp. 1-30.

[14] C. Zhu, D. Fan, Z. Duan, W. Xue, L. Shang, F. Chen, Y. Luo, J. Biomed. Mater. Res. A 2009, $89,829$.

[15] A. Moshaverinia, S. Ansari, C. Chen, X. Xu, K. Akiyama, M. L. Snead, H. H. Zadeh, S. Shi, Biomater. 2013, 34, 6572. 
[16] S. M. H. Khaled El-Tahlawy, J. Appl. Polym. Sci. 2006, 100, 1162.

[17] M. G. Cascone, N. Barbani, C. Cristallini, G. Ciardelli, L. Lazzeri, Biomater. Sci., Polym. Ed. 2014, 12, 267.

[18] Y. K. Y. Suzuki, Y. Nishimura, M. Tanihara, K. Suzuki, A. Ki. Kitahara, Y. Yamawaki, T. Nakamura, Y. Shimizu, J. Artif. Organ. 1998, 1, 28.

[19] L. Wang, E. Khor, A. Wee, L. Y. Lim, J Biomed Mater Res. 2002, 63, 610.

[20] R. Jayakumar, M. Prabaharan, P. T. S. Kumar, S. V Nair, H. Tamura, Biotechnol. Adv. 2011, 29,322 .

[21] R. Jayakumar, M. Prabaharan, P. T. S. Kumar, In Biomedical Engineering, Trends in Materials Science; 1990; pp. 3-25.

[22] M. Kucharska, M. H. Struszczyk, M. Cichecka, K. Brzoza-malczewska, Prog. Chem. Appl. Chitin Its Deriv. 2011, XVI, 131.

[23] J. Jagur-grodzinski, Polym. Adv. Technol. 2006, 17, 395.

[24] X. Shao, C. Hunter, J. Biomed. Mater. Res. A 2007, 82, 702.

[25] R. Pallela, J. Venkatesan, V. R. Janapala, S. Kim, Wiley Period. Inc. 2011, 100, 486.

[26] S. A. Martel-estrada, C. A. Martínez-pérez, J. G. Chacón-nava, P. E. García-casillas, I. Olivasarmendariz, Carbohydr. Polym. 2010, 81, 775.

[27] T. F. and H. T. N. Nwe, Mater. 2009, 2, 374.

[28] A. J. Steward, Y. Liu, D. R. Wagner, Biomater. Regen. Med. 2011, 63, 74.

[29] C. K. Kuo, P. X. Ma, Biomateri. 2001, 22, 511.

[30] A. Salimi, M. Ghollasi, N. Saki, F. Rahim, A. Dehghanifard, A. Sh, M. Hagh, M. Soleimani, IJBC 2010, 3, 11.

[31] C. Young, P. D. Rekha, W. Lai, A. B. Arun, Wiley Period. Inc. 2006, 95, 76.

[32] N. E. Vrana, A. O. Grady, E. Kay, P. A. Cahill, G. B. Mcguinness, J. Tissue Eng. Regen. Med. 2009, 3, 567.

[33] K. S. V. K. Rao, B. V. Kumar, M. C. S. Subha, M. Sairam, T. M. Aminabhavi, Carbohydr. Polym. 2006, 66, 333.

[34] Kashappa Goud H. Desai1 and Hyun Jin Park, Drug Dev. Res. 2005, 128, 114. 
[35] A. Rieux, N. Duhem, C. Je, Adv. Polym. Sci. 2011, 244, 19.

[36] S. J. Sarma, K. Pakshirajan, B. Mahanty, J. Chem. Technol. Biotechnol. 2011, 86, 266.

[37] A. Belščak-cvitanović, R. Stojanović, V. Manojlović, D. Komes, I. Juranović, V. Nedović, B. Bugarski, Food Res. Int. 2011, 44, 1094.

[38] M. Bhavan, G. Nagar, Int. J. Appl. Biol. Pharm. Technol. 2011, 2, 402.

[39] S. Rajeshkumar, C. Venkatesan, M. Sarathi, V. Sarathbabu, J. Thomas, K. A. Basha, A. S. S. Hameed, Fish Shellfish Immunol. 2009, 26, 429.

[40] M. Machluf, Biopolym. 2006, 82, 570.

[41] E. A. El-hefian, M. M. Nasef, A. H. Yahaya, Aust. J. Basic Appl. Sci. 2011, 5, 670.

[42] W. T. Godbey, B. S. S. Hindy, M. E. Sherman, A. Atala, Biomater. 2004, 25, 2799.

[43] S. H. Oh, J. H. Lee, Biomed. Mater. 2013, $8,1$.

[44] S. L. T. and M. J. Y. Jing Yao, Polym. 2011, 3, 899.

[45] L. S. Nair, C. T. Laurencin, Prog. Polym. Sci. 2007, 32, 762.

[46] M. R. Kumar, Bull Mater. sci. 1999, 22, 905.

[47] V. Bansal, P. Sharma, N. Sharma, Advan. Biol. Res. 2011, 5, 28.

[48] Y. Qin, J. Appl. Polym. Sci. 2004, 91, 2.

[49] Y. Qin, Polym. Adv. Technol. 2008, 19, 6.

[50] S. Hirano, Macromol. Symp. 2001, 168, 21.

[51] M. Dash, F. Chiellini, R. M. Ottenbrite, E. Chiellini, Prog. Polym. Sci. 2011, 36, 981.

[52] E. Khor, L. Yong, Biomater. 2003, 24, 2339.

[53] R. Song, R. Xue, L. He, Y. Liu, Q. Xiao, Chinese J. Polym. Sci. 2008, 26, 621.

[54] H. Xie, S. Zhang, S. Li, Green Chem. 2006, 8, 630.

[55] K. Y. Lee, D. J. Mooney, Prog. Polym. Sci. 2012, 37, 106.

[56] N. Iwasaki, S. Yamane, T. Majima, Y. Kasahara, Biomacromol. 2004, 5, 828.

[57] J. Chang, Y. Lee, M. Wu, M. Yang, C. Chien, Carbohyd. Polym. 2012, 87, 2357.

[58] J. Wang, X. Huang, J. Xiao, N. Li, W. Yu, W. Wang, W. Xie, X. Ma, Y. Teng, J. Mater. Sci. 2010, 21, 497.

[59] A. Niekraszewicz, D. CiechaÅ,,ska, Fiber Text. East. 2006, 14, 25. 
[60] M. Todaro, A. Quigley, M. Kita, J. Chin, K. Lowes, A. J. Kornberg, M. J. Cook, R. K. Ã, Human. 2007, 28, 1.

[61] A. J. Konop, R. H. Colby, Macromol. 1999, 32, 2803.

[62] S. A.-A. and G. O. P. Syed K. H. Gulrez, In Progress in Molecular and Environmental Bioengineering - From Analysis and Modeling to Technology Applications; 2003; pp. 117149.

[63] F. Elahi, W. Lu, G. Guoping, F. Khan, J. Bioeng. Biomed. Sci. 2013, 3, 1.

[64] C. Tangsadthakun, S. Kanokpanont, N. Sanchavanakit, T. Banaprasert, S. Damrongsakkul, J. Met. Mater. Miner. 2006, 16, 37.

[65] A. Hussain, G. Collins, D. Yip, C. H. Cho, Biotech. Bioeng. 2012, 110, 1.

[66] S. Koo, S. J. Ahn, Z. Hao, J. . C. Wang, E. K. Yim, Cell. Mol. Bioeng. 2011, 4, 399.

[67] L. Wang, C. Li, Y. Chen, S. Dong, X. Chen, Y. Zhou, Biomed. Res. Int. 2013, 06/2013, 1.

[68] P. Dutta, K. Rinki, J. Dutta, Chit. Biomater. II 2011, 244, 45.

[69] P. B. Malafaya, G. a Silva, R. L. Reis, Adv. drug. Del. Rev. 2007, 59, 207.

[70] A. F. Quigley, K. J. Bulluss, I. L. B. Kyratzis, K. Gilmore, T. Mysore, K. S. U. Schirmer, E. L. Kennedy, M. O’Shea, Y. B. Truong, S. L. Edwards, G. Peeters, P. Herwig, J. M. Razal, T. E. Campbell, K. N. Lowes, M. J. Higgins, S. E. Moulton, M. A. Murphy, M. J. Cook, G. M. Clark, G. G. Wallace, R. M. I. Kapsa, J. Neural Eng. 2013, 10, 1.

[71] A. R. Costa-Pinto, R. L. Reis, N. M. Neves, Tissue Eng. B 2011, 17, 331.

[72] E. Newkirk, I. Aliferis, Anal. Chem. 1958, 30, 982.

[73] J. P. Soares, J. E. Santos, G. O. Chierice, E. T. G. Cavalheiro, Eclet. Quím. 2004, 29, 53. 


\section{Figures and Captions}

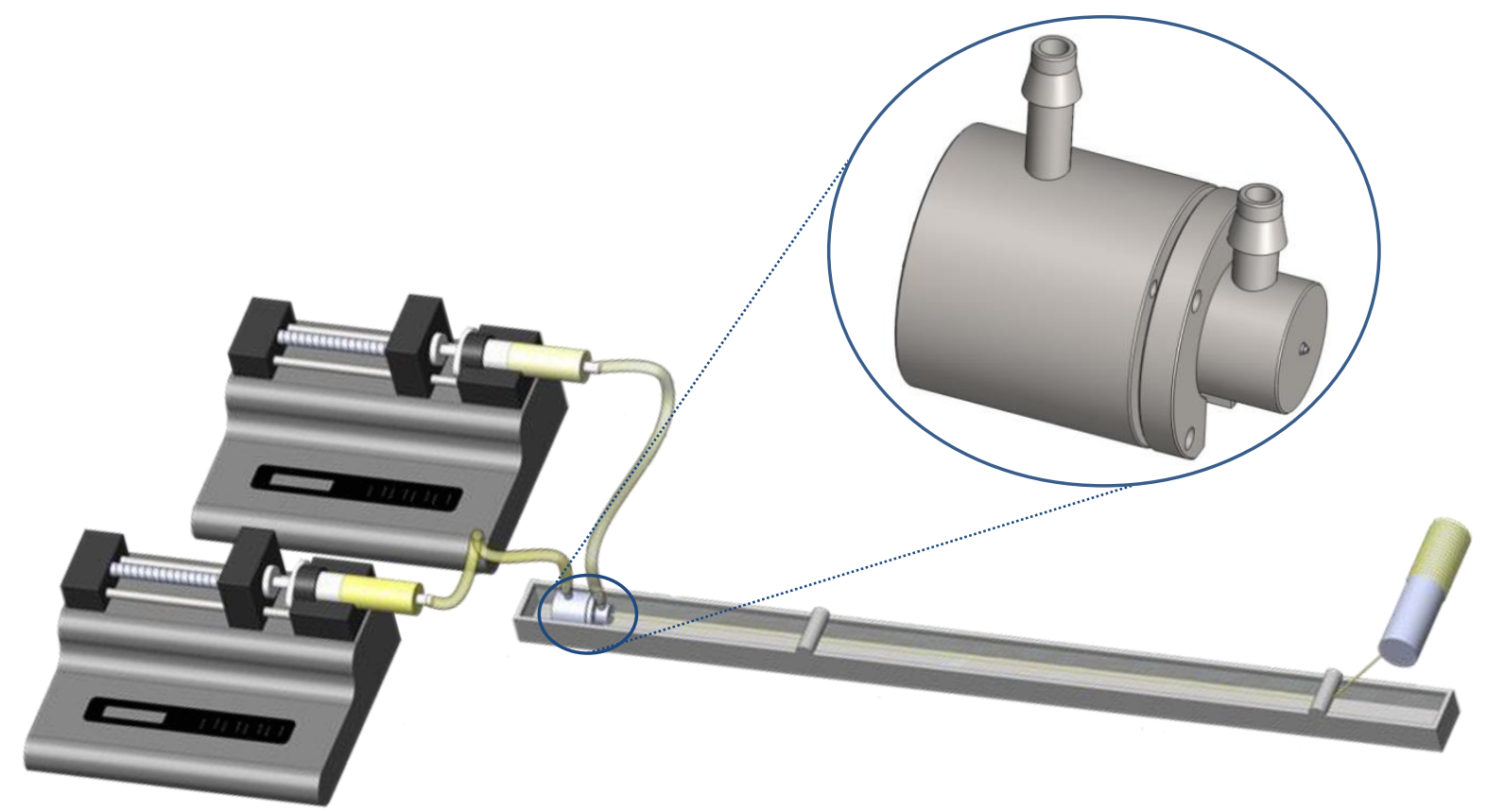

Figure 1 A schematic for coaxial wet-spinning setup

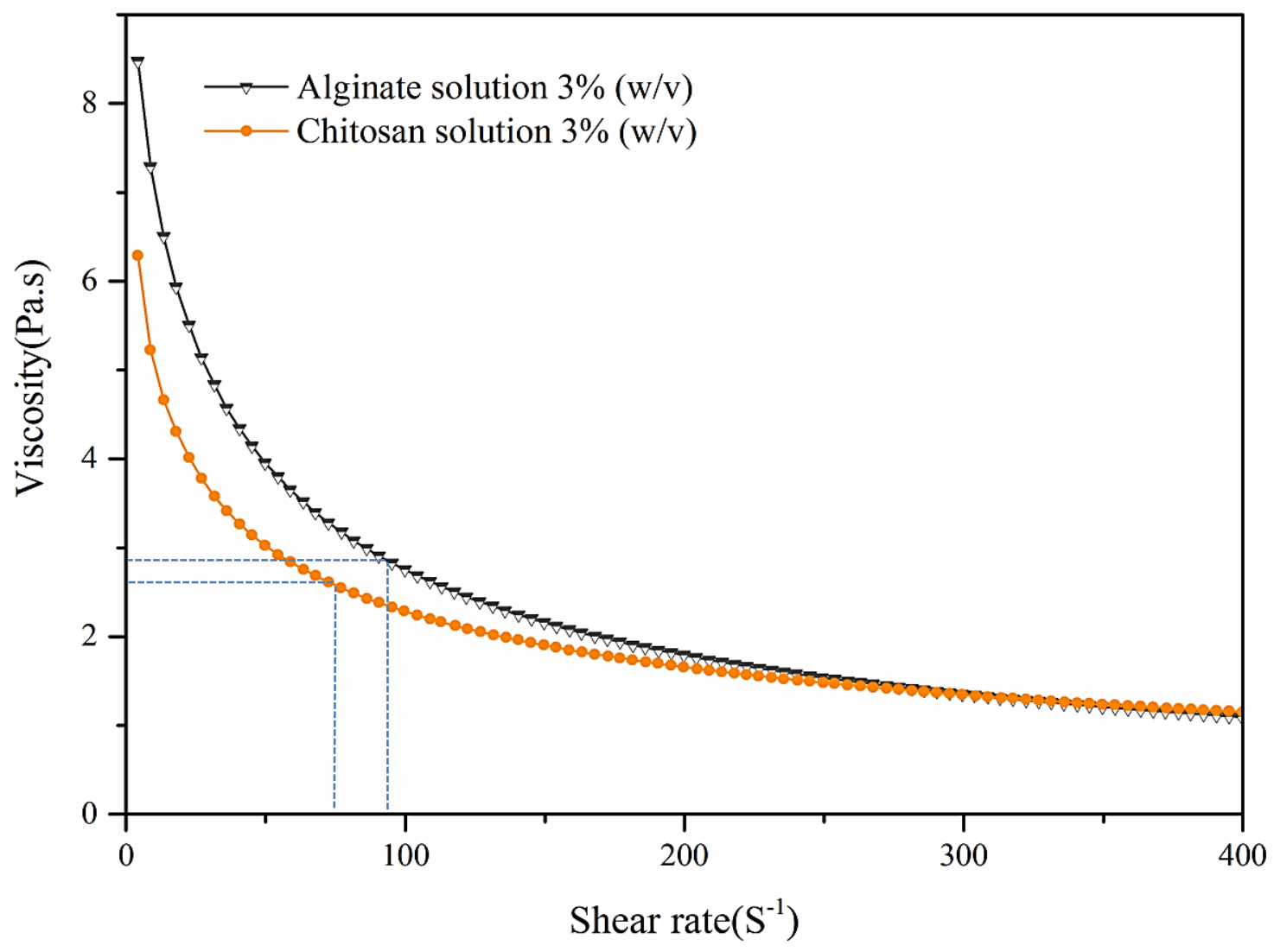

Figure 2 Viscosities of spinning solutions of chitosan and sodium alginate 


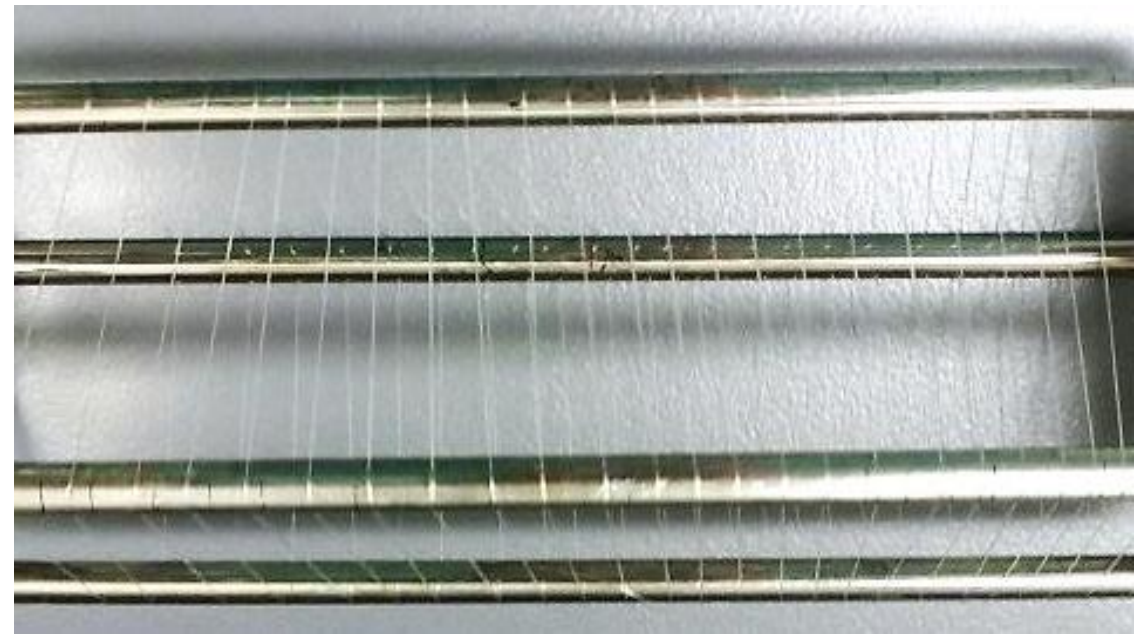

Figure 3 The capability of producing unlimited length of coaxial Chit-Alg (1) fibres as shown onto a collector

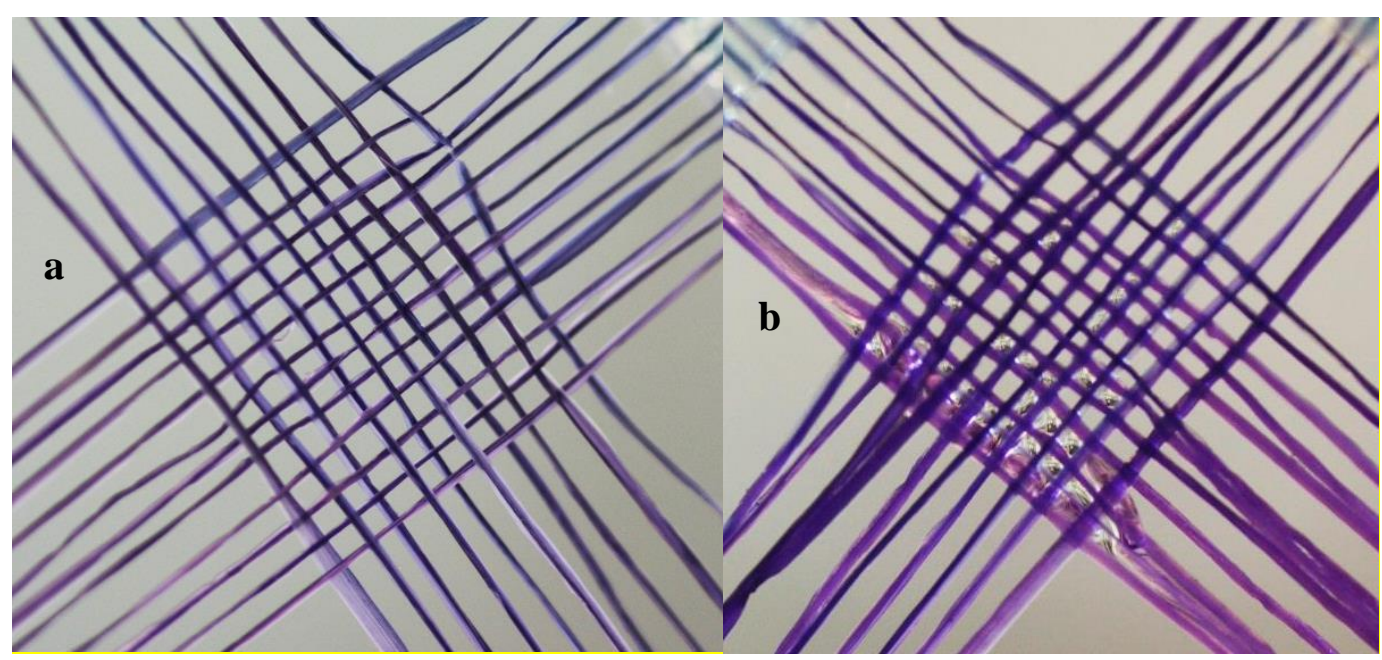

Figure 4 The photographs of scaffold structure woven by coaxial fibres; imaged in (a) dry state and (b) wet-state 


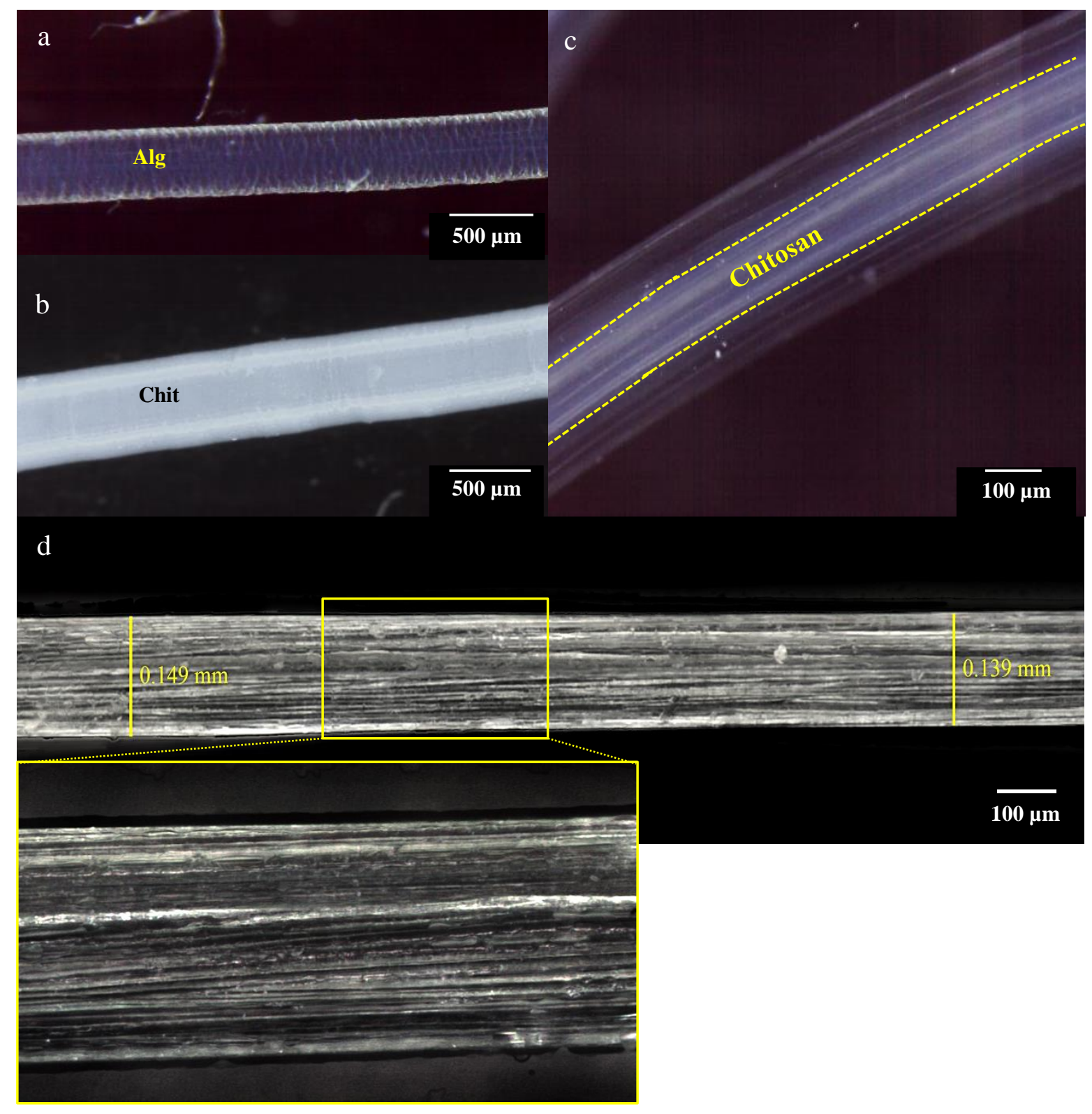

Figure 5 Stereomicroscope images of side view of wet (a) alginate, (b) chitosan, (c) coaxial Chit-Alg (1) and (b) dry Chit-Alg (1) fibre 


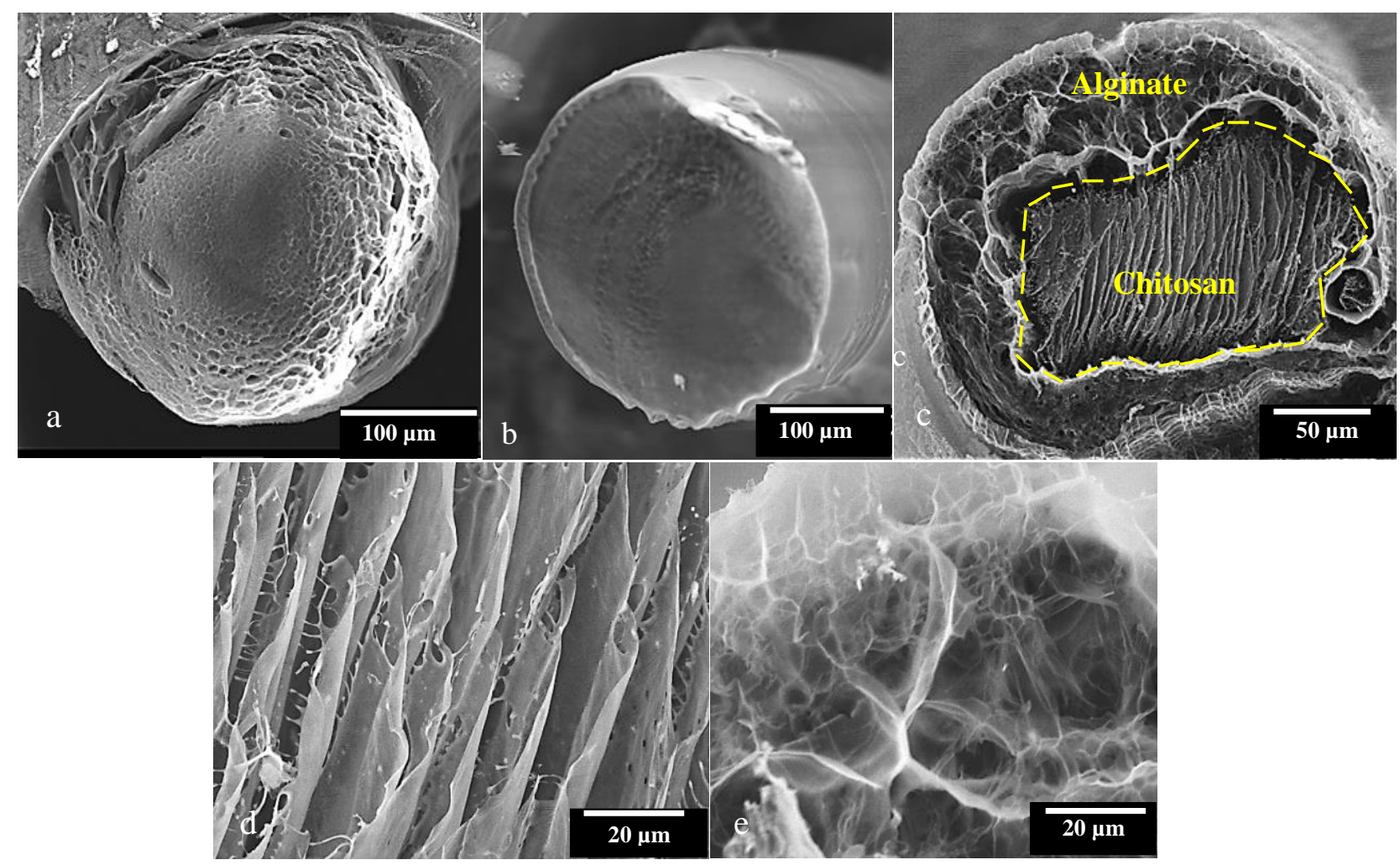

Figure 6 LV-SEM images of hydrated as-prepared (a) alginate, (b) chitosan and (c) Chit-Alg (1) cross section in SBF, (d) chitosan core arrangement in cross section (e) alginate sheath construction in the cross Section 


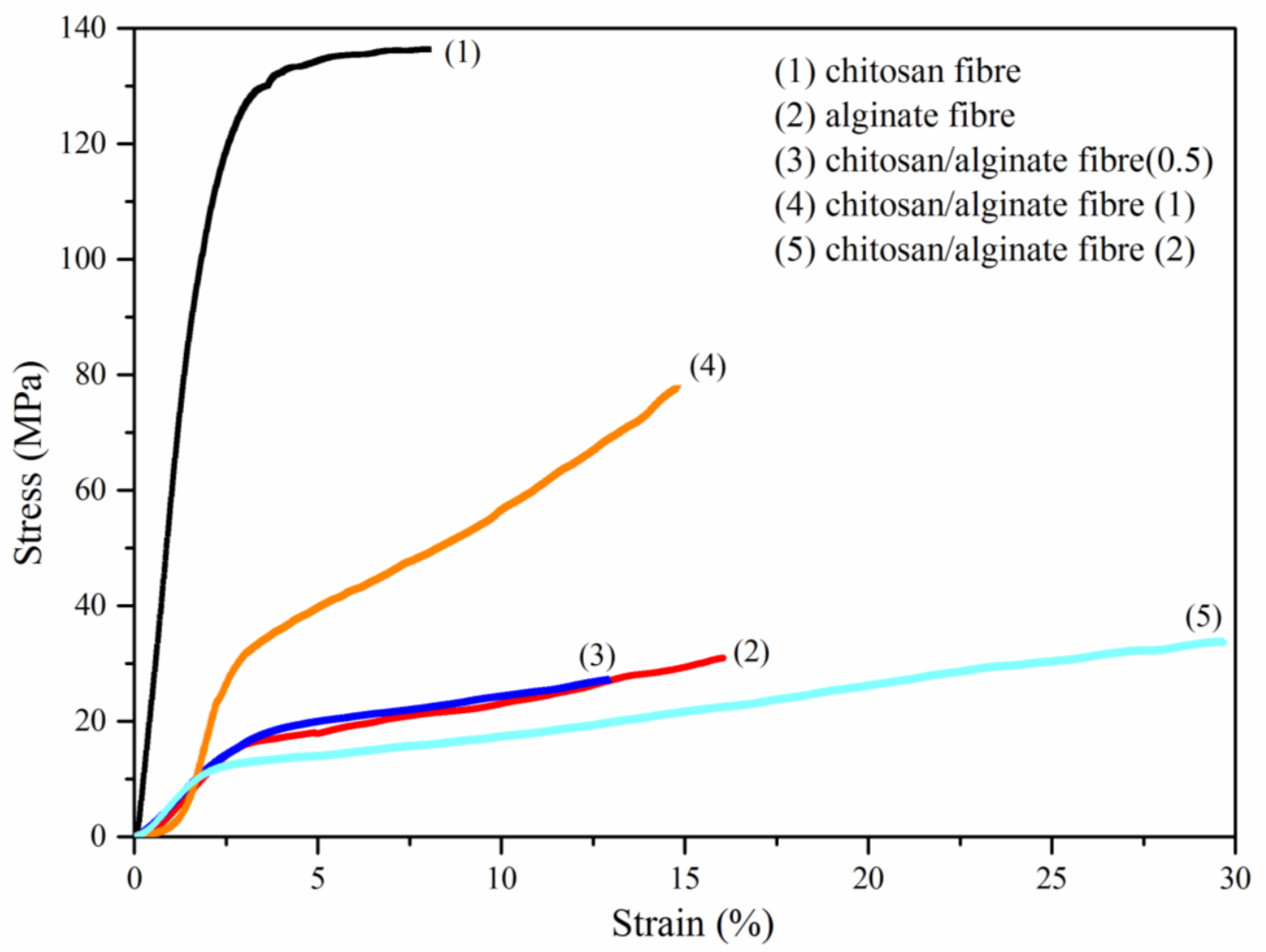

Figure 7 Stress-strain curves obtained from tensile tests of alginate single and chitosan/alginate coaxial fibres using different $\mathrm{CaCl}_{2}$ concentrations 


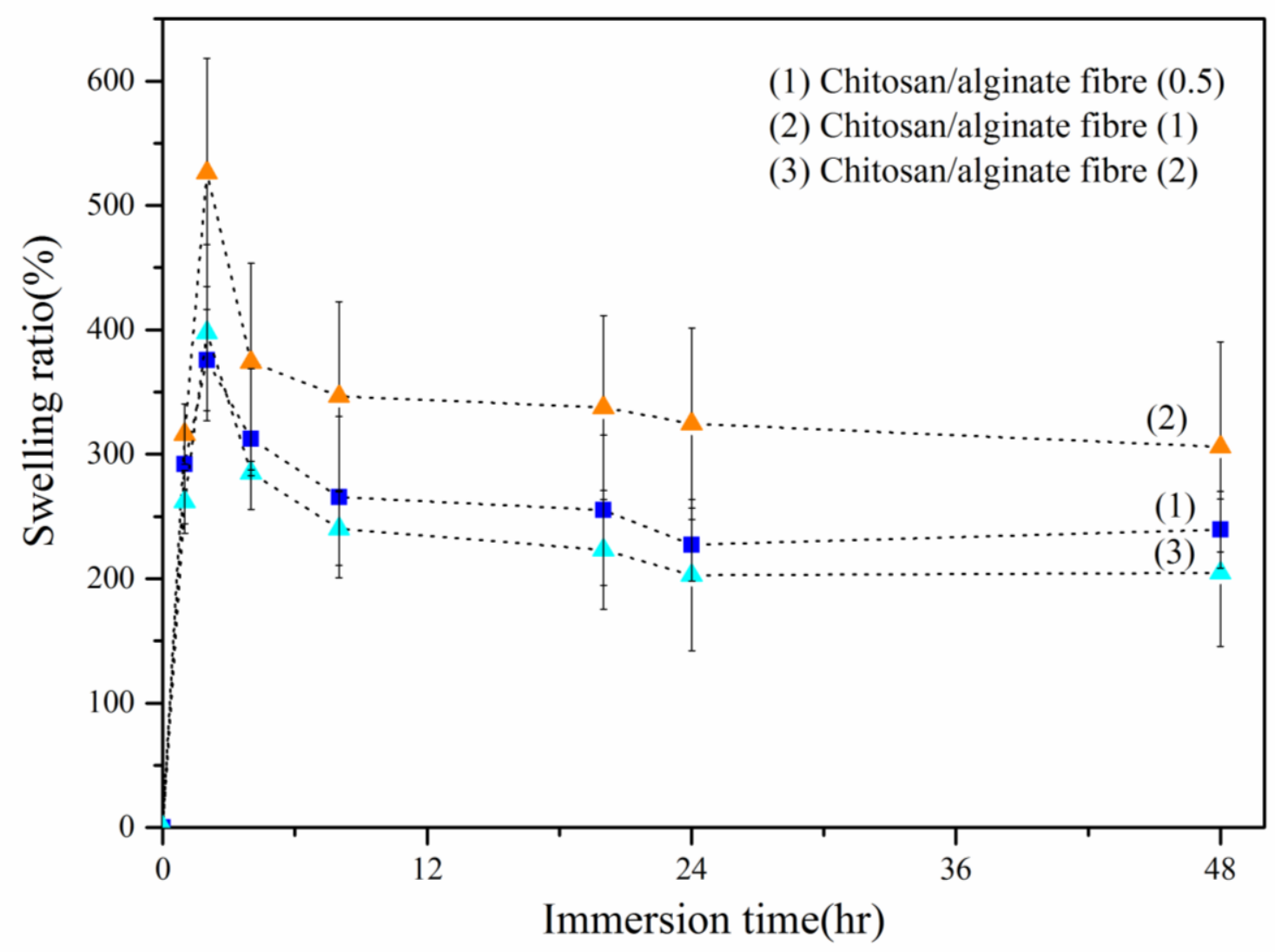

Figure 8 Swelling properties of coaxial wet-spun fibres in SBF as a function of the immersion time

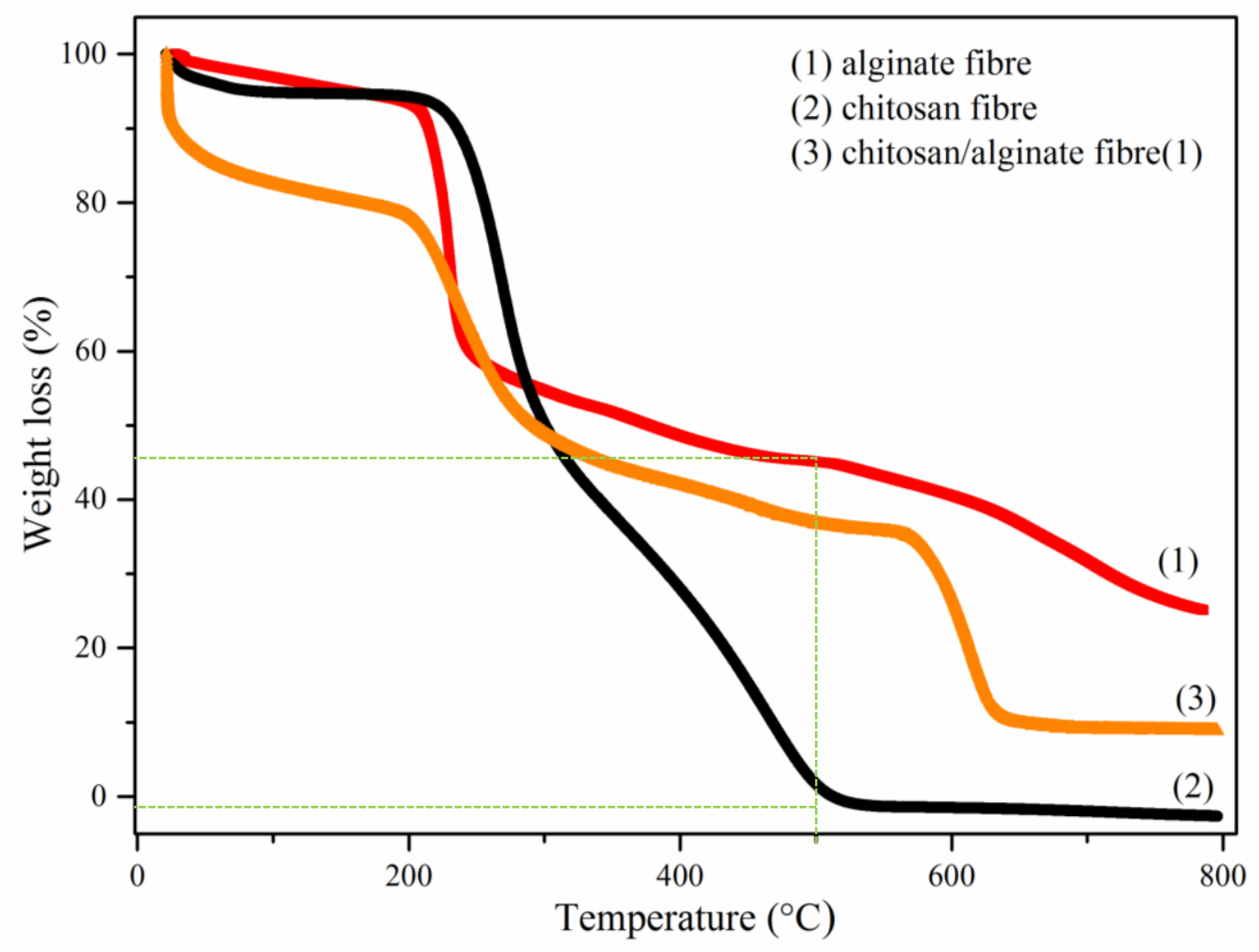

Figure 9 TG curves of alginate, chitosan and coaxial Chit-Alg (1) fibres 


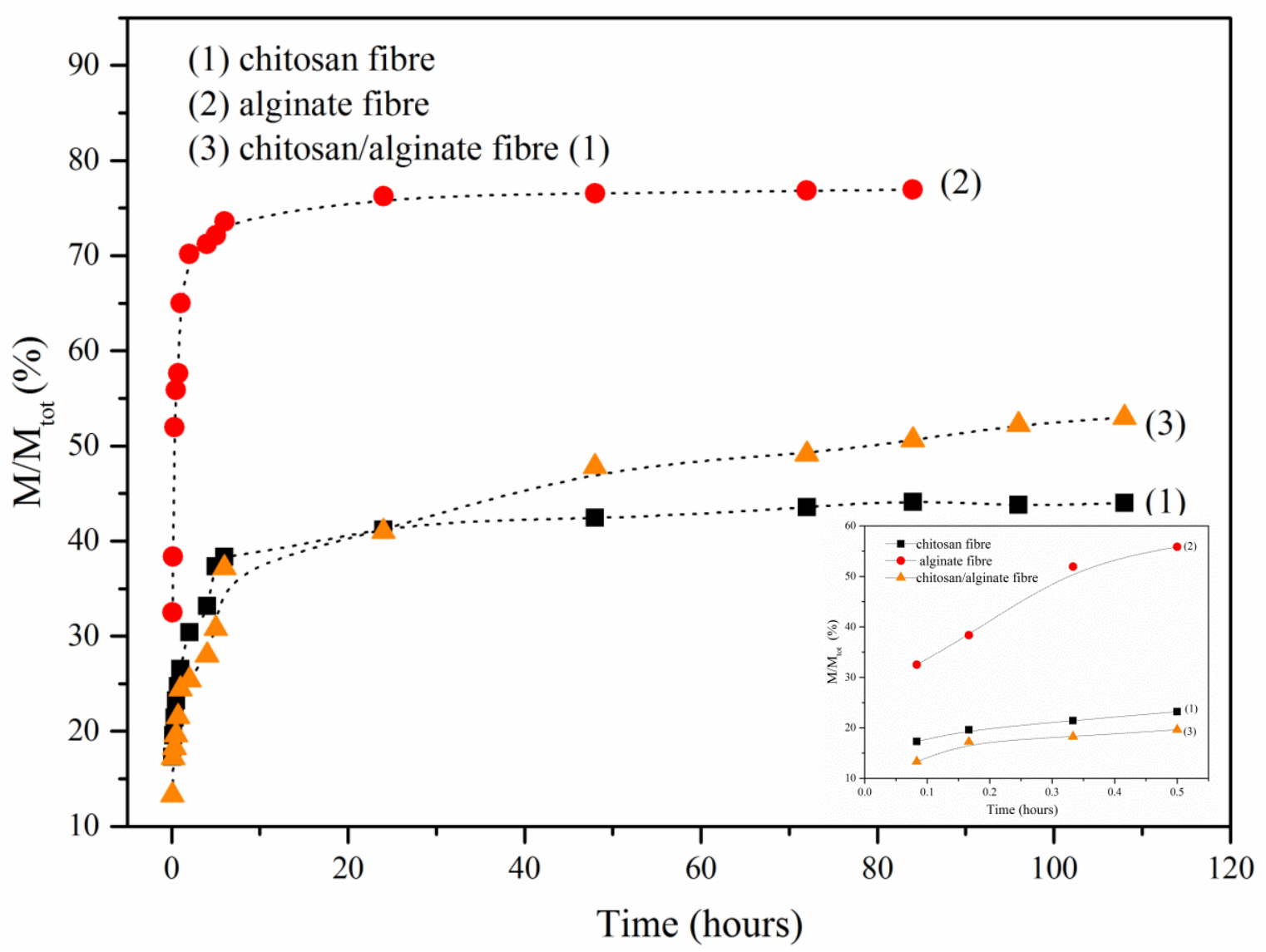

Figure 10 Time dependent TB releasing behaviour of chitosan, alginate and chitosan/alginate hydrogel fibres in SBF at $37^{\circ} \mathrm{C}$. Inset; burst release of coaxial fibres in the first 30 minutes 


\section{Tables}

Table 1 Comparison of mechanical properties of solid and coaxial biofibres

\begin{tabular}{ccccc}
\hline Sample & Breaking stress (MPa) & Strain at break (\%) & Young's modulus(MPa) & $\begin{array}{c}\text { Initial swelling ratio } \\
(\%)\end{array}$ \\
\hline Calcium alginate fibre & $\sim 31 \pm 5$ & $\sim 26 \pm 3$ & $16 \pm 1.5$ & $>500$ \\
Chitosan fibre & $\sim 146 \pm 30$ & $\sim 19 \pm 10$ & $66 \pm 8$ & (Non-measurable) \\
Chit-Alg (0.5) & $\sim 30 \pm 5$ & $\sim 22 \pm 8$ & $6 \pm 1$ & $\sim 360$ \\
Chit-Alg (1) & $\sim 80 \pm 10$ & $\sim 14 \pm 3$ & $19 \pm 2$ & $\sim 540$ \\
Chit-Alg (2) & $\sim 28 \pm 5$ & $\sim 37 \pm 5$ & $5.5 \pm 1$ & $\sim 385$ \\
\hline
\end{tabular}




\section{Supporting Information}

\section{Development and Characterization of Novel Hybrid Hydrogel Fibres}

Azadeh Mirabedini, Javad Foroughi*, Tony Romeo, Gordon G. Wallace*

ARC Centre of Excellence for Electromaterials Science, Intelligent Polymer Research Institute, AIIM

Facility, University of Wollongong, Fairy Meadow, NSW 2519, Australia

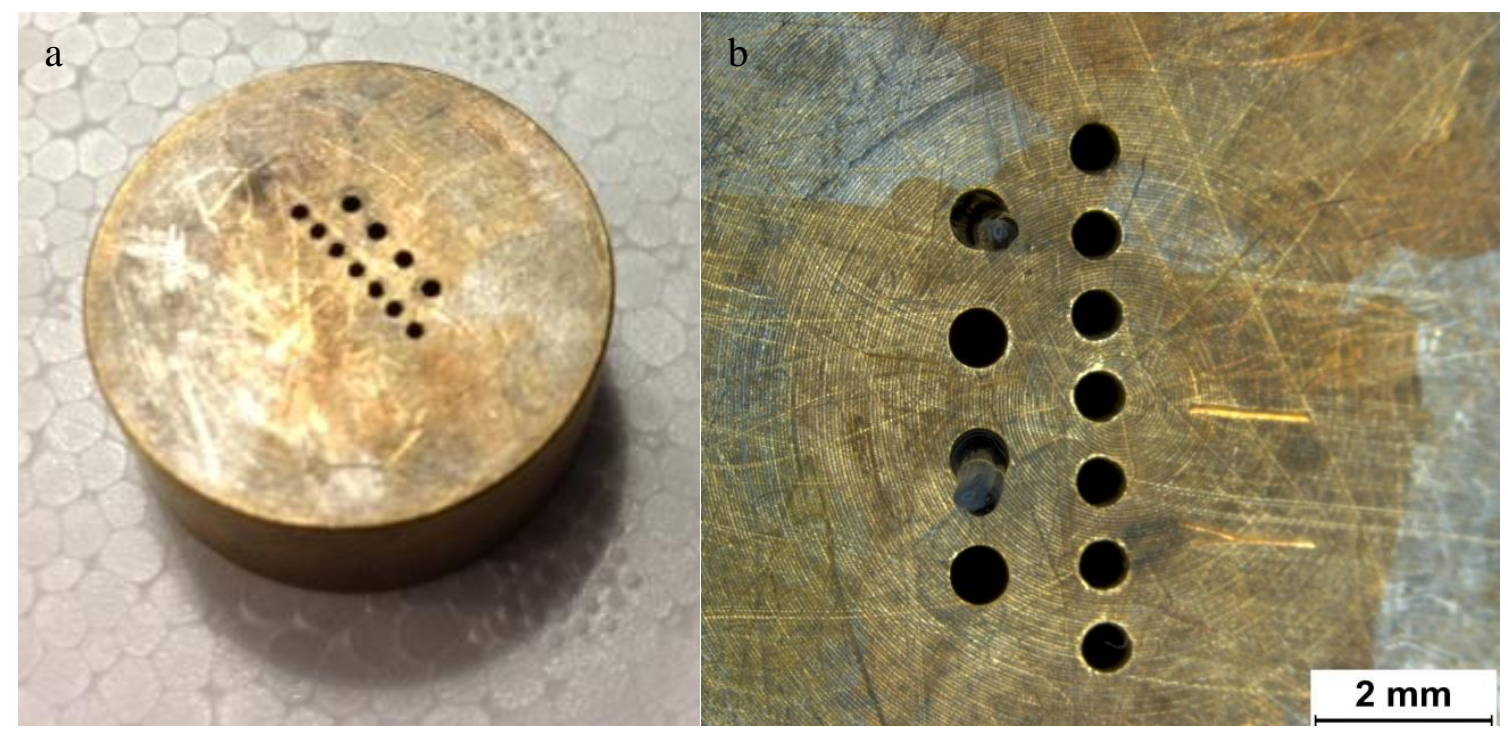

Figure 1 (a) $25 \mathrm{~mm}$ x 10mm pre-drilled brass block, (b) wet fibres inserted upright into the holes and protrude from the brass block to be imaged under LVSEM 


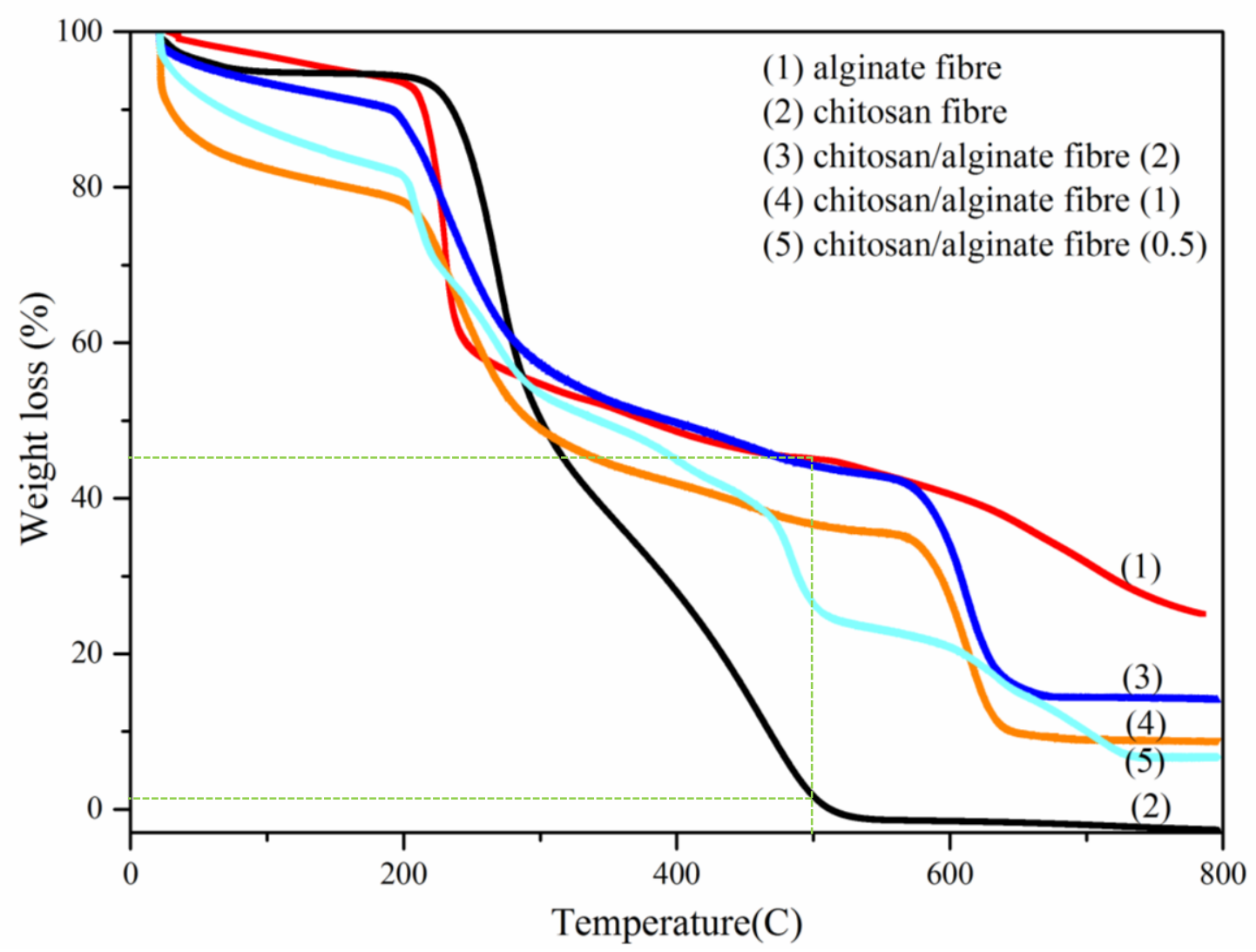

Figure 2 TG curves of single and coaxial fibres 